\title{
Researching student perspectives on interprofessional online learning via asynchronous text-based conferencing in healthcare education: A literature review
}

\author{
Jennifer Chiok-Foong Loke \\ Faculty of Health and Social Care, University of Hull, England \\ Correspondence: Jennifer Chiok-Foong Loke. Address: Aire 224, Faculty of Health and Social Care, University of Hull. \\ Cottingham Road, HU6 7RX, England. Telephone: 44-1482-463-460. E-mail: J.loke@hull.ac.uk
}

Received: October 8, 2011

Accepted: December 22, 2011 Published: May 1, 2012

DOI : 10.5430/jnep.v2n2p141

URL: http://dx.doi.org/10.5430/jnep.v2n2p141

\begin{abstract}
Background: There is an increasing important role for asynchronous text-based computer mediated conferencing as a pedagogic tool in interprofessional learning for nurses in higher education. Available research studies on asynchronous text-based interprofessional learning at post-registration level based on either users' perspectives or the conference communication provided useful information on students' learning experience. This paper first discusses the theoretical assumptions of asynchronous text-based interprofessional learning. The purpose is to highlight the way student online learning experience might be created. Based on this knowledge, the paper goes on to describe and discuss the research methodologies and methods, with less emphasis on the kind of results that have been obtained in the field of study about asynchronous text-based interprofessional online learning within nursing education at post-registration level.
\end{abstract}

Methods: The literature search focuses on papers which investigate student perspectives on the experience on effectiveness of asynchronous text-based interprofessional online learning. Criteria for inclusion were papers about the use of computer mediated conferencing at post-registration level for interprofessional online learning by nurses and healthcare professionals allied to health.

Results: Reviewing the body of research about student perspectives on post-registration students' experience with interprofessional online learning revealed that asynchronous text-based conferencing at post-registration healthcare programmes which involved nurses had received insufficient research attention in nurse, health and social education research literature. Only seven papers were available for review. In addition, the research methods and approaches employed have not been consistent with the pedagogic principles and ideas associated with principles of collaborative learning through communication based on constructivism.

Conclusion: Research studies to inform strategies for asynchronous text-based interprofessional online learning in postregistration nurse education might be limiting. There is a need for more research, especially those which commensurate with the constructivist approach in learning. Certainly, research using discourse analysis which focuses on the discursive aspect and communication needs to be conducted to evaluate asynchronous text-based interprofessional online learning. 


\section{Key words}

Asynchronous text-based conferencing, Discourse, Interprofessional learning, Health professions education and nurse education

\section{Introduction}

All around the globe, there has been a growing awareness of the importance of interprofessional learning in healthcare education for cultivating collaborative ${ }^{[1-4]}$ and quality patient care ${ }^{[5,6]}$. In the United Kingdom, under the Labour Government initiatives, interprofessional learning in healthcare education was largely based in higher education. In the case of nurse education, a greater emphasis was placed on pre-registration programmes designed for those seeking registration as a professional nurse with the nursing regulatory bodies. Nevertheless, opportunities for interprofessional learning for nursing at post-registration level for Master's programmes or for stand-alone modules aimed at continuous professional development have been increasingly provided by many local universities. For these programmes, asynchronous text-based conferencing with the use of type-written text posted to the virtual learning space for online communication and discussion was commonly used as a pedagogic tool for interprofessional learning at post-registration level ${ }^{[7,8]}$. Post qualifying nursing students who are professional nurses in practice and who might otherwise be unable to participate in any interprofessional learning due to family and work commitment could then have the opportunity to benefit from learning collaboratively from and with other healthcare professionals ${ }^{[9]}$.

Similarly in other parts of the world, notably in Canada, despite the introduction of newer technologies as pedagogic tools, asynchronous text-based online learning for post-registration nurse programmes appears to have maintained its popularity for interprofessional learning ${ }^{[10]}$. Hence, it might be reasonable to assume that many healthcare educators have gone past the stage of deciding if asynchronous text-based on-line learning should replace traditional face-to-face classroom teaching at post-registration level for interprofessional learning ${ }^{[10]}$. However, whilst assuming that, it is important to recognize that stemming from the established stereotyping of professional identities and specialised disciplinary knowledge between professionals ${ }^{[11,12]}$, the lack of face-to-face interactions in asynchronous text-based online learning may pose severe challenges to collaborative interprofessional learning. For this reason, there might be some healthcare educators who are still sceptical about the use of the technology in fulfilling the healthcare agenda of interprofessional learning.

Indeed, it has been identified that the stereotyping of professional identities and specialised disciplinary knowledge between professionals could potentially be magnified in a text-based learning environment ${ }^{[13]}$. Yet the impetus for text-based online-learning to fulfill the interprofessional learning agenda within healthcare education in higher learning has continued to be intense, particularly in nursing programmes. For this reason, research work was likely to have been conducted on a continuous basis to uncover the interprofessional online learning experience, especially those based on student perspectives.

This paper reviews the specific body of research which has a focus on students' experience based on student perspectives of the effectiveness of asynchronous text-based interprofessional online learning participated by nurses at postregistration level. The interests of this paper are the research methodologies and methods with less emphasis on the results that have been obtained in the field of asynchronous text-based interprofessional online learning. To help with the understanding of the concern of the research approach in the field of asynchronous text-based conferencing, this paper first discusses the theoretical assumptions in asynchronous text-based interprofessional online learning. It then reports on the search methodology and the results of the search. Based on the understanding that existing research methods are limiting the knowledge of healthcare student online experience, this paper makes recommendations for future research in interprofessional online learning in post- registration level healthcare programmes. 


\section{Theoretical origins of text-based interprofessional online learning}

Vygotsky ${ }^{[14]}$ asserts that both participation in social interaction and symbolically mediated thought facilitated by dialogue and language are important for individual learning. Vygotsky further uses his concept of the 'zone of proximal development' (ZPD) to emphasize that learning is effective with the help of not only more able adults but also with the help from peers. Reflecting in Vygotsky's idea of active interdependent learning role of learners through dialogue and his concept of ZPD is the nature of adult role in learning which greatly influenced the implementation of asynchronous computer mediated conferencing in interprofessional learning ${ }^{[14]}$.

In asynchronous text-based interprofessional online learning, the mediation of speech is in the form of typed-texts which is sent to a common site where they are accessible to students who are assumed to have the characteristics of adult learners for successful interprofessional learning. This assumption is based on the theoretical grounding of adult learning that within interprofessional learning, healthcare professionals as mature learners are believed to be intrinsically motivated, self directed, reflexive and critical in thinking ${ }^{[15]}$. Through a text-based communication process, nurses and professionals from various healthcare disciplines could therefore benefit from and with each other's learning through sharing and critically reflecting on each other' perspectives that might have been unique to a specific healthcare profession ${ }^{[1,7]}$. Based on Vygotsky's ${ }^{[14]}$ social learning constructivism theory, the technology allows views which were once closed from some healthcare professionals to be opened up in peer interactions in the form of a text-based dialogue. In this regard, whilst allowing ‘co-reflection' in interprofessional learning ${ }^{[16]}$ for deep learning ${ }^{[17]}$, asynchronous text-based conferencing is where student online learning experience is created.

Other than Vygotsky's ${ }^{[14]}$ social learning constructivism theory, Bakhtin's dialogical theory ${ }^{[18]}$ was also used in asynchronous text-based interprofessional online learning. In Bahktin's ${ }^{[18]}$ work with poststructuralist ideas of language, communication and identity, he explains that productivity and creativity of discourse practice and its realisation in texts are heterogeneous in their forms and meanings. For Bakhtin, the construct of discourse is simultaneously influenced by individual's inwardly persuasive discourses as well as by any authoritative discourses that guard and contour people's social actions. Bakhtin ${ }^{[18]}$ therefore believes speech as discourse is open and provisional in the way that produces knowledge.

Based on Bahktin's idea, the type-written texts generated in asynchronous text-based conferencing are directly translated by the speakers' speeches. The translation as a form of discourse which is the speakers' own speeches is also, part others'. Relating Bahktin's dialogical concept to interprofessional online learning; the key point of learner control in the constructivist discourse is that learning happens in a real life context. The resources which learners use to perform their discursive acts are rich in content as they are derived from the learners' personal and professional contexts. In asynchronous text-based conferencing, learners can choose from their real life context to engage in a flexible and open dialogue. Any alternate views which might be part others' are complementary professional perspectives that can be brought together to meet for a joint innovative perspective ${ }^{[19]}$. It is apparent that these interactional processes requiring the involvement of radical and creative thinking and learning which contribute to important intentional outcomes of interprofessional learning in post registration healthcare programmes is influencing the student online learning experience.

\section{Methods}

A literature search was first conducted via the main data bases in nursing, namely, CINAHL and MEDLINE. An electronic search was then continued online via EBSCOhost, Ovid and ScienceDirect, all of which are important search platforms for healthcare and nurse education research papers. The search was followed by another electronic search from SwetsWise database which provides access to a growing range of journal titles. The use of SwetsWise was to avoid missing any relevant papers that were not published as nursing or healthcare education literature. 
The search was limited to those published in English, but without any restriction as to when they were published. This search strategy was employed with an appreciation that there was a world-wide expansion of the use of technologies in higher education ${ }^{[20]}$. Notably in the United Kingdom, when the government initiatives for interprofessional learning were implemented, the view of e-learning as an emerging approach to life-long learning and flexible learning for health and social care education and practice by the National Health Service was still strongly held ${ }^{[9,21-26]}$ that research efforts in evaluating asynchronous text-based interprofessional online learning were continuous. Key words such as 'interprofessional learning', 'nurse/nursing education', 'asynchronous computer conferencing', 'text-based learning' 'post- registration' and post- qualifying' were used for the search.

\section{Results}

\subsection{Number and characteristics of research studies}

Seven papers were included in the current literature review (see Table 1). A quorom statement of flow diagram explains how these seven papers were selected (see Figure 1). This small volume of research papers on interprofessional online learning at post-registration level not only confirmed the insufficient research attention of interprofessional online learning given to nurse and healthcare education ${ }^{[27]}$, but also highlighted the persistent lack of research efforts devoted in this area. Six of the seven research studies ${ }^{[8,28-30]}$ were clearly about nurses in mix-disciplinary online learning. The paper in this literature review by Zhu ${ }^{[32]}$ did not specify if the undergraduate and postgraduate healthcare student populations in the online discussions comprised registered nurses.

Albeit the lack of information in terms of the participants' specific healthcare disciplines and professional qualifications, Zhu's ${ }^{[32]}$ paper was included in the current review for two main reasons. Firstly, nurses are usually well represented in any mixed discipline learning group due to the sheer number of nurses in healthcare. Thus, the group of post graduate healthcare students in Zhu's ${ }^{[32]}$ was likely to comprise nurses. Secondly, a phenomenon of small-sized discussion group, which was only observed in post- registration healthcare programmes was reflected in the study in Zhu's ${ }^{[32]}$. For these reasons, including Zhu's ${ }^{[32]}$ in the current review would not allow the relevant paper to be missed by mistake. Hence, Zhu's ${ }^{[32]}$ was included and this resulted in the total of seven papers in the current review.

With regards to the aim of all 7 research papers, each had a clear focus to evaluate student experience in terms of the efficiency of the asynchronous text-based conferencing technology as a pedagogic tool. However, whilst six research studies ${ }^{[1,8,28-31]}$ evaluated this from the users' perspectives, only two of the $\operatorname{six}^{[28,30]}$ had done so with a focus on the online communication patterns. The remaining paper by $\mathrm{Zhu}^{[32]}$ had a focus on the interactional patterns of discussions, but it was aimed at establishing the levels of student cognitive engagement through the analysis.

This observation was made despite the fact that underpinned asynchronous text-based interprofessional learning is Vygotsky's ${ }^{[14]}$ social constructivist learning and Bakhtin's dialogical theory, that this form of learning was based on communication, albeit it being translated into type-written text and conducted online asynchronously. Based on Vygotsky's ${ }^{[14]}$, the concept of 'zone of proximal development' was used to explain how student-centred learning was achieved through social interactions and symbolically mediated thought facilitated by dialogue and language conducted in the form of type-text by students. In an interprofessional learning situation at post-registration level, Vygotsky's ${ }^{[14]}$ theory is coupled with Bakthin's ${ }^{[18]}$ dialogical theory to explain the way 'dialogues' in asynchronous online learning were created; that the online communication was based on the resources students, as experienced healthcare professionals drew from their rich personal and professional contexts.

However, these resources from each individual unique profession used for discussions appeared to have attributed to the stereotyping of professional identities and specialised disciplinary knowledge between professionals ${ }^{[29]}$. Due to the lack of a face-to-face element in communication, these attributions which were detrimental to the student learning experience 
could potentially be magnified in a text-based learning environment ${ }^{[13]}$. In this regard the discursive aspect should have been the focus of these studies.

Table 1. Research papers included in the literature review

\begin{tabular}{|c|c|c|c|c|}
\hline Authors & Nature of sample & Research methods & Researchers & $\begin{array}{l}\text { Relevant Findings for current } \\
\text { review }\end{array}$ \\
\hline $\begin{array}{l}\text { Bacigalupo } \\
\text { et al., } 2001 .\end{array}$ & $\begin{array}{l}\text { Nursing; Midwifery, } \\
\text { physiotherapy (PT), } \\
\text { pharmacy, public health, } \\
\text { health promotion, health } \\
\text { services, management and } \\
\text { information technology }\end{array}$ & $\begin{array}{l}\text { Student feedback } \\
\text { Observation of } \\
\text { online behavior }\end{array}$ & $\begin{array}{l}\text { Course } \\
\text { developers }\end{array}$ & $\begin{array}{l}\text { 1.course materials made available } \\
\text { online as no value add but the } \\
\text { module provided good peer support } \\
\text { 2. decreased use of technology close } \\
\text { to course work deadline/Discussions } \\
\text { dominated by a minority few }\end{array}$ \\
\hline $\begin{array}{l}\text { Becker et } \\
\text { al., } 2000\end{array}$ & $\begin{array}{l}\text { Nurse, OT, pharmacy, } \\
\text { physiotherapy (PT), respire } \\
\text { care, social work (SW), and } \\
\text { speech \& language therapy } \\
\text { (SLT). }\end{array}$ & Surveys & $\begin{array}{l}\text { Course } \\
\text { developers }\end{array}$ & $\begin{array}{l}\text { Student had negative view on } \\
\text { interdisciplinary team working }\end{array}$ \\
\hline $\begin{array}{l}\text { Jordan, } \\
2001 .\end{array}$ & $\begin{array}{l}\text { Nursing, Medicine, PT, OT, } \\
\text { podiatry, SLT, orthoptics, } \\
\text { midwifery and osteopathy }\end{array}$ & $\begin{array}{l}\text { 1.Content Analysis of } \\
\text { conference discussions } \\
\text { from evaluative study of } \\
\text { the programme } \\
\text { 2. Questionnaires } \\
\text { 3. Interviews }\end{array}$ & Independent & $\begin{array}{l}\text { The majority of students considered } \\
\text { that they had benefited from the } \\
\text { collaborative environment, a } \\
\text { minority felt frustrated by the } \\
\text { requirements for collaboration }\end{array}$ \\
\hline $\begin{array}{l}\text { Juntunen \& } \\
\text { Heikkinen, } \\
2004\end{array}$ & Nursing, SW \& PT & $\begin{array}{l}\text { Student feedback } \\
\text { (included likert scales, } \\
\text { open and closed } \\
\text { questions) }\end{array}$ & $\begin{array}{l}\text { Course } \\
\text { developers }\end{array}$ & $\begin{array}{l}\text { Most critical challenges were in the } \\
\text { ability to supervise, support and } \\
\text { motivate students in collaborative } \\
\text { learning }\end{array}$ \\
\hline $\begin{array}{l}\text { Lund et al., } \\
2002\end{array}$ & $\begin{array}{l}\text { Nurses, residents, attending } \\
\text { physicians, and paramedics }\end{array}$ & Self-reported surveys & $\begin{array}{l}\text { Course } \\
\text { developers }\end{array}$ & $\begin{array}{l}95 \% \text { of participants would } \\
\text { participate in future online modules }\end{array}$ \\
\hline $\begin{array}{l}\text { Sandars \& } \\
\text { Langlois, } \\
2006 .\end{array}$ & $\begin{array}{l}2 \text { cohorts including directors } \\
\text { of public Health, doctors and } \\
\text { public health specialists } \\
1 \text { cohort including only } \\
\text { general practitioners with } \\
\text { different special interests }\end{array}$ & $\begin{array}{l}\text { 1.Semi-structured } \\
\text { telephone interviews on a } \\
\text { purposive sample of four } \\
\text { members from each case } \\
\text { 2.Documentary analysis } \\
\text { of all self-reported } \\
\text { comments made } \\
\text { in conference discussion }\end{array}$ & $\begin{array}{l}\text { Course } \\
\text { developers }\end{array}$ & $\begin{array}{l}\text { 1.initial burst of enthusiasm in the } \\
\text { discussion board } \\
\text { 2. As time progressed the number of } \\
\text { postings to the discussion began to } \\
\text { drop }\end{array}$ \\
\hline $\begin{array}{l}\text { Zhu, E., } \\
2006 .\end{array}$ & $\begin{array}{l}4 \text { groups; } 1 \text { HC students, } \\
1 \text { post qualifying HC;2 } \\
\text { non-healthcare (HC) }\end{array}$ & $\begin{array}{l}\text { Content analysis and } \\
\text { social network analysis of } \\
\text { conference data }\end{array}$ & Independent & $\begin{array}{l}\text { Star/Web type interaction pattern - } \\
\text { determined by presence of moderate } \\
\text { instructor participation }\end{array}$ \\
\hline
\end{tabular}

Apparently, other than the three research studies by Bacigalupo et al. ${ }^{[28]}$, Jordan and Zhu ${ }^{[28,30,32]}$, none of the other papers were designed to evaluate the effectiveness of the technology for interprofessional online learning in terms of the communication processes within the online learning environment. Also, when Zhu ${ }^{[32]}$ had a specific focus on the interactional patterns of discussions, the study was not aiming to examine users' experience based on their perspectives. 
This observation was made despite the fact that the established stereotyping of professional identities and specialised disciplinary knowledge between professionals which adversely affected interprofessional learning ${ }^{[11,12]}$ might have been attributed to problematic communication that could have been exaggerated in a text-based learning environment where social cues for effective communication were absent ${ }^{[27]}$.

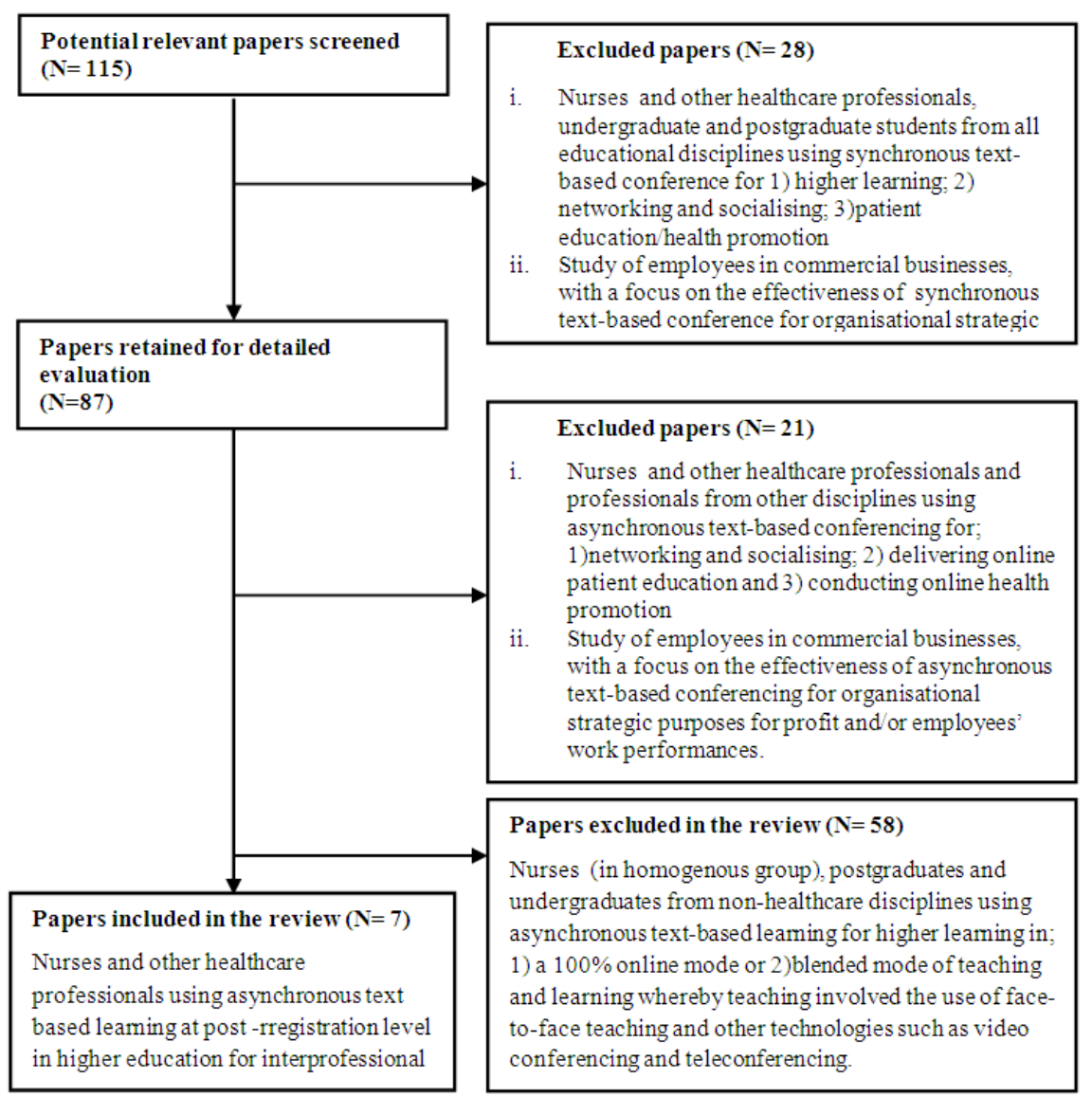

Figure 1. A quorom statement of flow diagram demonstrating paper selection

\subsection{Research methods employed in the research studies}

Two research studies ${ }^{[29,31]}$ were quantitatively based using only self-report surveys to establish users' perspectives on their learning experience. Four others ${ }^{[1,8,28,30]}$ employed mixed-method approaches which involved interviews and survey-based feedback to seek better understanding of the users' experience. Nevertheless, two of these four ${ }^{[28,30]}$, also included content analysis of the conference discussions. By doing so, not only were the student's accounts of their online experience verified by the online behaviour in the naturally occurring interprofessional online learning situation, the cause and implications of student online learning experience were also better understood.

Similarly, the research by Zhu ${ }^{[32]}$ included the conference discussions as data for content analysis. However, unlike others ${ }^{[28,30]}$, Zhu ${ }^{[32]}$ had extended her analysis from content analysis to a structural approach which involved social network analysis. As such, Zhu ${ }^{[32]}$ was able to establish the unique patterns in the online discussions which revealed either a star type or web type of interaction. The former was characterised by a centralized, either uni-directional or bidirectional 
interaction resulting from the same few minority students always taking the lead in discussions and dominating discussions; the latter was characterised by a democratising virtual learning environment where students interacted well with each other. By combining social network analysis with content analysis of the conference discourse, the different online communication patterns were established by Zhu ${ }^{[32]}$, who was then able to reveal more about the students' experience; that was, a web type interaction was common in the healthcare students' communication, however this was only observed in the presence of a moderate amount of instructor participation.

The trend of using self-report surveys predominantly, and later, supplemented by qualitative approaches in which the conference texts were analysed to uncover the phenomenon of learners' experience, which might suggest that a relativist's view in which the perspective of those involved was eventually considered essential for evaluating the effectiveness of interprofessional online learning. Nevertheless, the assumption of researchers about reality might still be what Morgan and Smircich ${ }^{[33]}$ described in a positivistic (or traditional) perspective; that 'reality' as a concrete structure in which 'people' became the adapters, responders, and information processors working towards achieving efficiency and the originally set goals. In this regard, albeit the fact that qualitative approach was subsequently used to supplement the quantitative approaches, student learning experience was still not critically examined, but rather impressionistically described.

Indeed, whether content analysis or social network analysis was used to evaluate the effectiveness of interprofessional online learning from student perspectives, none of the studies critically analysed the learners' experience; Based on Vygotsky's ${ }^{[14]}$ social constructivist learning theory and Bahktin's ${ }^{[18]}$ dialogical theory, contributing to student interprofessional online learning experience was the discursive element as part of social life ${ }^{[34]}$. In other words, the interactional communication process can be based on students' personal or professional life contexts, both of which are outside the online virtual leaning environment. Yet none of the elements of real life context were taken into account by previous studies. In the analyses, the discursive element as part of social life ${ }^{[34]}$ was persistently separated from it, such that there was no analysis of what occurred beyond the immediate context of the conference. This was the case even when content analysis was used; be it on its own ${ }^{[30]}$ or in combination with social network analysis ${ }^{[32]}$, the analyses were still in isolation of social analyses of practices beyond the context of the conference. Consequently, the remainder of social life which affected text production was still placed outside the discourse in the analyses. Yet, the theoretical assumptions in interprofessional online learning are based on an ontological view in which students in the social construction of reality are believed to bring with them the variable interpretative resources to bear on the text ${ }^{[34]}$.

Based on this literature review, effectiveness of interprofessional online learning as indicated by student learning experience, was indeed derived from the interactions based on communication in the asynchronous text-based interprofessional online learning environment. The interactions might have in turn been affected by what went on beyond the immediate context of the conference. However, the research methods employed in all studies had introduced a clear distinction between the discursive (text in the conference) and the extra discursive (students' social practices). For this reason, the analyses might not be able to explain what occurred beyond the text, nor could it explain the intertwined relationship between text and social practices in nursing and healthcare, and yet, both of which had significant contributions to students’ interprofessional online learning experience.

\subsection{Limitations of the methodological perspectives and approaches}

Based on Vygostsky's ${ }^{[14]}$ and Bakthin's ${ }^{[18]}$ concepts, interprofessional online learning may have emerged from a social constructivist and a dialogic view in learning. In essence, it seeks to capitalize on the opportunities that communications technologies offer collaboration between the healthcare professionals. Yet, many research studies aimed at establishing the effectiveness of interprofessional online learning, used self report accounts as a research method to uncover the students' learning experience. As such, these investigations could never go beyond an anecdotal account which in actual fact, could only provide an impressionistic view of the student learning experience. Furthermore, since researchers were usually the course developers, many of these accounts through student feedback and interviews might have been distorted due to the power difference between the participants and the researchers ${ }^{[35]}$. Two studies in particular ${ }^{[30,32]}$ might have appreciated the limitations of interviews and had supplemented interviews with content analysis of text and structural 
analysis of student perspectives. However, the analyses were within the confined space of the conference, without addressing the dialogical approach to co-constructing knowledge in interprofessional online learning.

There was indeed, little suggestion that published research studies had adopted the methodological perspectives and methods which commensurate with the values and ideas of collaborative constructivist learning in interprofessional online learning. On the contrary, existing evidence suggests that research studies continue to be positioned towards the objective end of the methodological perspective continuum. Since research methods had been based more on an epistemological view and shaped by positivism, they were not likely to take into account the co-construction of experience based on a relativist's view. So far, whilst studying student experience required researchers to include the social element in the analysis, the latter was never considered in any research work. Hence, the interactive practices had never been critically examined. When this happened, a partial view of the phenomenon might have been established and the understanding of students' interprofessional online learning experience, even if it was based on the users' perspective, would have been examined at a superficial level.

Notwithstanding the methodological limitations, the findings gleaned from previous research studies have offered invaluable insights to some decision making in interprofessional online learning. Nevertheless, without any of these studies being able to uncover what was actually happening in the conference based on a larger social perspective, any constructive support that had been offered was more likely to have been based on a limited view of the online experience. Consequently, any strategies for effective interprofessional online learning were not likely to have reached their full potentials for success.

\section{Recommendations}

Asynchronous text-based collaborative learning emerges from Vygotsky's ${ }^{[14]}$ social learning constructivism theory and Bakhtin's dialogical theory ${ }^{[18]}$. Based on these theories, any prior experience and knowledge of learners were believed to have been brought with the student participants for co-construction of knowledge in interprofessional online learning. Keeping this concept in mind, it is important to also understand the notion of discourse as social action rather than a 'do nothing domain', that it involved work of all who participated to co-produce meaning ${ }^{[36,37]}$. In this view, students' interprofessional online learning experience was co-produced dialogically via online text-based communications by the online participants.

For this reason, students' experience as useful information for evaluating interprofessional online learning was likely to be embedded in the conference texts. This makes any conference discourse generated during interprofessional online learning an invaluable research data. In this light, discourse analysis might be a viable supplementary research tool to existing research methods in evaluating the effectiveness of interprofessional online learning. Inasmuch as discourse analysis is based on the notion of discourse as social action ${ }^{[37]}$, it commensurates with a constructivist view and would be an ideal research tool to evaluate the effectiveness of asynchronous text-based interprofessional online learning.

By employing discourse analysis of the naturally generated conference data, there is also less concern for distorted views altered unknowingly from participants being forgetful or on purpose due to participants feeling the need to address the power relations that exist between them and the researchers. By using discourse analysis of the conference discussions which are produced naturally in an authentic learning environment, any inevitable pitfalls in qualitative research which sought to elicit information based on interviews or anecdotal accounts of the participants ${ }^{[35]}$ can be addressed.

\section{Conclusion}

Due to the increasing importance of interprofessional learning in healthcare education, constructivist approaches to teaching and learning using asynchronous text-based conferencing finally gained their foothold in nurse education, 
particularly at post- registration level. Based on this literature review, none of the research methodologies and methods to investigate effectiveness of interprofessional online learning is consistent with a constructivist approach to this form of learning. The research approaches to evaluate interprofessional learning in nurse education are still very much in line with the longstanding, pedagogical allegiance to the tenets of logical positivism and instructivism. Critically, research attention is not given adequately to what is considered to be the most appropriate way of researching interprofessional online learning. The processes at work within the text-based environment which affected students' interprofessional online learning experience are not likely to have been adequately analysed.

Notwithstanding the limitations of existing research methods, understanding of the students' experience created in a constructivist approach to online discussion is gleaned. However uncovering the multifaceted and complex issues of interprofessional online learning experience was not possible. In this view, discourse analytic approaches which are consistent with the theoretical assumptions underpinning asynchronous text-based interprofessional learning should arguably be employed as a viable research method for evaluating the interprofessional online learning experience in any post-registration nurse programmes.

\section{Acknowledgement}

I would like to thank Bryant Ken Lee for his thoughtful review of the initial drafts and Dr Gloria Likupe for her comments on the final.

\section{References}

[1] Juntunen, A., Heikkinen, E. Lessons from interprofessional e-learning: piloting a care of the elderly module. Journal of Interprofessional Care. 2004; 18: 269-278. PMid:15369970 http://dx.doi.org/10.1080/13561820410001731313

[2] Loke, J.C.F., Colquhoun, D., Lee, K.W. Critical Discourse Analysis of Interprofessional Online Learning in Health Care Education. New York: Nova Science Publisher. 2011.

[3] Reeves, S., Freeth, D. The London training ward: an innovative interprofessional learning initiative. Journal of Interprofessional Care. 2002; 16: 41-52. PMid:11915715 http://dx.doi.org/10.1080/13561820220104159

[4] Turner, P., Sheldon, F., Coles, C., Mountford, B., Hillier, R., Radway, P., Wee, P. Listening to and learning from the family carer's story: an innovative approach in interprofessional education. Journal of Interprofessional Care. 2000; 14: 387-395. http://dx.doi.org/10.1080/13561820020003937

[5] McPherson, K., Headrick, L., Moss, F. Working and learning together: good quality care depends in it, but can how can we achieve it? Quality in Health Care. 2001; 10: 46-53.

[6] McWilliam, C., Sangster, F. Managing patient discharge to home: The challenges of achieving quality of care. International Journal of Quality in Health Care. 1994; 6:147-161. PMid:7953214

[7] Connor, C. Virtual learning and interprofessional learning education: developing computer mediated communication for learning about collaboration. Innovations in Education and Teaching International. 2003; 40: 341-347. http://dx.doi.org/10.1080/1470329032000128379

[8] Sandars, J., Langlois, M. Online collaborative learning for healthcare continuing professional development: lessons from the recent literature. Education for Primary Care (EDUC PRIM CARE). 2006; 17: 584-592.

[9] United Kingdom Centre for the Advancement of Interprofessional Education (CAIPE). Interprofessional Education - a definition. CAIPE Bulletin. 1997; 13:19.

[10] King, S., Greidanus, E., Carbonaro, M., Drummond, J., Patterson, S. Merging Social Networking Environments and Formal Learning Environments to Support and Facilitate Interprofessional Instruction. Med Educ Online. 2009; 14:5. http://dx.doi.org/10.3885/meo.2009.T0000132

[11] Hojat, M., Fields, S., Rattner, S., Griffiths, M., Cohen, M., Plumb. J. Attitudes toward Physician - Nurse Alliance: Comparisons of Medical and Nursing Students. Academic Medicine. 1997; 72:S1-S3. PMid:9347721 http://dx.doi.org/10.1097/00001888-199710001-00001

[12] Pollard, K. C. Non-formal learning and interprofessional collaboration in health and social care: the influence of the quality of staff interaction on student learning about collaborative behaviour in practice placements. Learning in Health and Social Care. 2008; 7:12-26. http://dx.doi.org/10.1111/j.1473-6861.2008.00169.x 
[13] Vroman, K., Kovacich, J. Computer-mediated interdisciplinary teams: theory and reality. Journal of Interprofessional Care. 2002; 16:159-170. PMid:12028896 http://dx.doi.org/10.1080/13561820220124175

[14] Vygotsky, L. S. Mind in society: The development of psychological processes. Cambridge, MA: Harvard University Press. 1978.

[15] Barr, H. Interprofessional education: today, yesterday and tomorrow: a review. (Other) London, UK: Higher Education Academy, Health Sciences and Practice Network. 2005.

[16] Wee, B. Working together and learning together: a collaborative Project. Final Report. Countess Mountbatten House and Moorgreen Hospital. Southampton. 1997.

[17] Koschmann, T. D. CSCL, theory and practice of an emerging paradigm. New Jersey: Laurence Erlbaum Associates Inc. 1996.

[18] Bakhtin, M. Speech genres and other late essays. Austin. Texas: Texas University Press. 1986.

[19] Johnson, P., Wistow, G., Schulz, R., Hardy, B. Interagency and interprofessional collaboration in community care: the interdependence of structures and values. Journal of Interprofessional Care. 2003; 17: 69-83. http://dx.doi.org/10.1080/1356182021000044166

[20] Duke, C. Managing the Learning University. Buckingham, UK: SRHE \& Open University Press. 2002.

[21] Department of Health (DH). A Health Service for all the talents: Developing the NHS workforce. London: Department of Health. 2000a.

[22] Department of Health (DH). The NHS Plan: A Plan for Investment, A Plan for Reform. London: Department of Health. 2000b.

[23] Department of Health (DH). Working together - Learning together - A framework for Lifelong Learning for the NHS. London: Department of Health. 2001.

[24] Department of Health (DH) and English National Board (ENB). Placements in Focus: Guidance for Education in practice for Health Care Professions. London: Department of Health and English National Board. 2001.

[25] National Health Service. Essence of Care: Patient Focused Benchmarks for Clinical Governance. Modernisation Agency. Leicester. 2003.

[26] National Health Service Executive. Clinical Governance. Leeds: NHS Executive. 1999.

[27] Loke, J.C. F. Computer mediated conferencing - A hope or hype for healthcare education in higher learning?: A review of the Literature. Nurse Education Today. 2007; 27: 318-324. PMid:16846669 http://dx.doi.org/10.1016/j.nedt.2006.05.012

[28] Bacigalupo, R. Bath, P. Booth, A., Eaglestone, B., Procter, P. Studying health informatics from distance: Issues, problems and experiences. Health Informatics Journal. 2001; 7:138-145. http://dx.doi.org/10.1177/146045820100700306

[29] Becker, E. A., Scott, A. H., Gutman, S., Zelski, L., Jaffee-Gropack, S., Kiefer, C., Riquelme, L., McManus, M., Nieves E. Creating interdisciplinary team practice through computer conferencing. Respiratory Care Education Annual Spring. 2000; 19-33.

[30] Jordan, G. A multi-disciplinary and international approach to postgraduate continuing professional development (CPD) for health professionals. Staff Development Seminar held at Institute of Physics. Report of the proceedings of the Staff Development Seminar, London. 2000; 14: 24-29. The Southern England Consortium for Credit Accumulation and Transfer c/o The University of East London: 2001 [Internet]. London. Available from: http://www.seec-office.org.uk/Changing\%20Professions.pdf

[31] Lund, A., Lam, K., Parks, P. Disaster medicine online: evaluation of an online, modular, interactive, asynchronous. The Journal of the Canadian Association of Emergency Physicians. 2002; 4:408-413.

[32] Zhu, E. Interaction and cognitive engagement: An analysis of four asynchronous online discussions. Instructional Science. 2006; 34:451-480. http://dx.doi.org/10.1007/s11251-006-0004-0

[33] Morgan, G., Smircich. L. The Case for Qualitative Research. Academy of Management Review. 1980; 5: 491-500.

[34] Fairclough, N. Critical Discourse Analysis: the critical study of language. England: Longman. 1995.

[35] Mason, J. Qualitative Researching London: Sage. 1996.

[36] Edwards, D. Discourse and Cognition London: Sage. 1997.

[37] Wetherell, M. Themes in Discourse Research: The Case of Diana. In M. T. Wetherell, S. Yates (Ed). Discourse Therapy and Practice. London: Sage. 2001; 14-28. 